\title{
Metabolic Alterations in the Human Erythrocyte Produced by Increases in Glucose Concentration
}

\author{
THE ROLE OF THE POLYOL PATHWAY
}

\author{
Susan F. Travis, Anthony D. Morrison, Rex S. Clements, Jr., \\ Albert I. Winegrad, and Frank A. Oski \\ From the Departments of Pediatrics and Medicine, University of Pennsylvania \\ School of Medicine, Philadelphia, Pennsylvania 19146 and The Children's \\ Hospital of Philadelphia, and the George S. Cox Institute, Department of \\ Medicine, Hospital of the University of Pennsylvania, \\ Philadelphia, Pennsylvania 19104
}

\begin{abstract}
A в S T RAC T Human erythrocytes incubated in medium containing $50 \mathrm{~mm}$ glucose have increased intracellular sorbitol and fructose concentrations as compared with samples incubated with $5 \mathrm{~mm}$ glucose. Increased medium glucose concentration did not significantly alter total glucose consumption or lactate production. However, the intracellular lactate: pyruvate ratio rose, the concentrations of fructose diphosphate, and triose phosphates increased, and the 2,3-diphosphoglycerate concentration fell. $\left[{ }^{14} \mathrm{C}\right] \mathrm{O}_{2}$ production from glucose- $1-{ }^{14} \mathrm{C}$ also increased with increased medium glucose concentration. These changes are believed to reflect changes in the redox states of the diphosphopyridine nucleotide/reduced form of diphosphopyridine nucleotide (NAD/NADH) and nicotinamide-adenine dinucleotide phosphate/reduced form of nicotinamideadenine dinucleotide phosphate (NADP/NADPH) couples resulting from increased activity of the polyol pathway. Addition of pyruvate to the incubation media prevented these changes. These studies illustrate that an increase in the red cell's normal substrate, glucose, can produce changes in red cell metabolism.
\end{abstract}

\section{INTRODUCTION}

The polyol pathway was thought to have restricted distribution in mammalian tissues, but recent studies have demonstrated that the initial enzyme of this sequence, aldose reductase, is present in most rat and rabbit tis-

A portion of this material was presented at the 40th Annual Meeting of The Society for Pediatric Research, May 1970, Atlantic City, N. J.

Received for publication 21 September 1970. sues $(1,2)$. The polyol pathway was first recognized in the accessory glands of the male genital tract (3) where it catalyzes the synthesis of seminal fluid fructose by the following reactions:

$$
\begin{aligned}
& \text { 1. D-Glucose + NADPH } \\
& +\mathrm{H}^{+} \underset{\text { (Alditol:NADP oxidoreductase) }}{\longrightarrow} \text { sorbitol }+\mathrm{NADP}^{+}
\end{aligned}
$$

2. Sorbitol

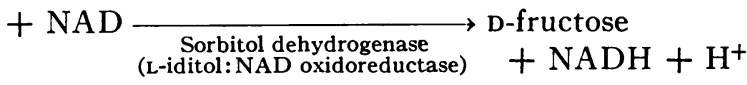

This reaction sequence appears to operate essentially irreversibly in intact seminal vesicles, lens, and aorta, where it has been studied most thoroughly.

Interest in the activity of the polyol pathway in tissues other than the seminal vesicles has centered on the pathological potential of increased polyol pathway activity in hyperglycemic states (4-7). The $K_{m}$ for glucose of the aldose reductases that have been isolated from lens and other tissues are of the order of $10^{-1}-10^{-2} \mathrm{M}(2,8-10)$ and the intracellular concentration of free glucose is thus a major determinant of the rate of sorbitol formation. Cataracts are consistently produced in lenses exposed to high concentrations of glucose and other substrates for aldose reductase (4). The striking changes in water content, in metabolic activity, and in fine structure of the lens that result from increased ambient glucose concentration, have been attributed to the osmotic consequences of the elevated sorbitol (polyol) levels in the lens cells (4).

In a previous report (11) we noted that sorbitol and free fructose are present in human erythrocytes in con- 
centrations that exceed those present in plasma. The erythrocyte levels of sorbitol and fructose increased with increasing ambient glucose concentration. When erythrocytes from normal males were incubated with $5 \mathrm{~mm}$ glucose, $3 \%$ of the glucose uptake was utilized for sorbitol and fructose synthesis. The fraction of the glucose uptake that could be accounted for by metabolism via the polyol pathway increased to as much as $11 \%$ when the medium glucose concentration was increased to $50 \mathrm{~mm}$. These observations suggested that the polyol pathway is normally operative in human erythrocytes, and that its activity could be increased by increasing ambient glucose concentration. The observations that form the basis of this report are concerned with the metabolic consequences of increased polyol pathway activity in human erythrocytes.

\section{METHODS}

Blood samples were collected from healthy male adults in tubes containing dried sodium heparin. ${ }^{1}$ The blood was centrifuged at $600 \mathrm{rpm}$ for $10 \mathrm{~min}$ in a Model $\mathrm{PR}-2^{2}$ centrifuge at $4^{\circ} \mathrm{C}$. The white cell and platelet-rich plasma were removed and the cells were washed three times with isotonic saline. Final erythrocyte suspensions contained less than 200 leukocytes $/ \mathrm{mm}^{3}$. The washed erythrocytes were resuspended in twice their volume of Krebs-Ringer bicarbonate buffer, $\mathrm{pH}$ 7.4. The flasks were supplemented with varying quantities of glucose so that the final concentrations ranged from 2 to $50 \mathrm{mM}$.

After a $25 \mathrm{~min}$ period of equilibration at room temperature, zero time samples were removed for the determination of glucose, lactic acid, pyruvate, hematocrit, and red cell, and medium sorbitol and fructose. Sampling was repeated after $2 \mathrm{hr}$ of incubation in a Dubnoff metabolic shaker, at $37^{\circ} \mathrm{C}$, at 80 oscillations $/ \mathrm{min}$. The atmosphere was $5 \% \mathrm{CO}_{2}$ in air. The $\mathrm{pH}$ of the samples was maintained at $7.40 \pm 0.02$.

The whole suspension was utilized for the determination of glucose, lactate, and the glycolytic intermediates. Determinations of fructose and sorbitol were performed on the cells and medium after they had been rapidly separated by centrifugation at $2500 \mathrm{rpm}$ for $5 \mathrm{~min}$ at $4^{\circ} \mathrm{C}$. In some experiments, as noted in the text, sorbitol was determined in neutralized perchloric acid extract of the whole suspension.

Glucose was assayed spectrophotometrically (12) on Somogyi-Nelson filtrates by means of yeast hexokinase ${ }^{8}$ and glucose-6-phosphate dehydrogenase. ${ }^{8}$ Lactate determinations (13) were performed spectrophotometrically on neutralized perchloric acid extracts of the whole suspension, unless stated otherwise. These same extracts were used for the determination of sorbitol, adenosine triphosphate (ATP), (14) and all glycolytic intermediates, except pyruvate. Pyruvate determinations (15) were performed on extracts prepared in $10 \%$ trichloracetic acid. Duplicate determinations of pyruvate on single specimens by this method did not vary by more than $2 \%$. Glucose-6-phosphate (G-6-P),

\footnotetext{
${ }^{1}$ Vacutainer, Becton-Dickenson \& Company, Rutherford, N. J.

2 International Equipment Co., Needham Heights, Mass.

${ }^{8}$ Boehringer-Mannheim Corporation, New York.

- Abbreviations used in this paper: DHAP, dihydroxyacetone phosphate; 2,3-DPG, 2,3-diphosphoglycerate; EGS,
}

fructose-6-phosphate (F-6-P), triose phosphates and fructose-1,6-diphosphate (F-1,6-diP), 3-phosphoglyceric acid (3-PGA), 2-phosphoglyceric acid (2-PGA), and phosphoenolpyruvate (PEP) were assayed fluorometrically employing an Eppendorf fluorometer ${ }^{5}$ (primary filter $\mathrm{Hg} 313$ $\pm 366 \mathrm{~nm}$, secondary filter 400 to $3000 \mathrm{~nm}$ ). Glucose-6-phosphate, F-6-P, dihydroxyacetone phosphate (DHAP), glyceraldehyde-3-phosphate (G-3-P), F-1,6-diP, 3-PGA, 2-PGA, and $\mathrm{PEP}$ were determined using the assay conditions described by Lowry, Passonneau, Hasselberger, and Schulz (16). Glyceraldehyde-3-phosphate, DHAP, and F-1,6-diP ("total triose phosphate") were assayed simultaneously as described by Keitt (17). 2,3-diphosphoglycerate (2,3-DPG) was determined spectrophotometrically by the Schröter and Heyden (18) modification of the method of Krimsky (19).

Sorbitol was determined by means of a fluorometric enzymatic assay using sheep liver Sorbitol dehydrogenase ${ }^{\circ}$ as previously described (10). This method is not specific for sorbitol since other polyol substrates such as xylitol may react under the conditions described. Xylitol was determined by means of a fluorometric enzymatic assay using xylitol: NADP oxidoreductase from pigeon liver.' Before use the commercial enzyme was dialyzed for $18 \mathrm{hr}$ against potassium phosphate buffer $(0.035 \mathrm{M}) \mathrm{pH} 7.0$, to remove glycerol. The complete system $(1.0 \mathrm{ml})$ contained 100 $\mu$ moles carbonate-bicarbonate buffer $\mathrm{pH} 9.6,0.05 \mu$ moles NADP, $5 \mu$ moles $\mathrm{MgCl}_{2}, 5 \mu$ moles 2-mercaptoethanol, and 0.025 IU of dialyzed xylitol: NADP oxidoreductase. The assay is linear over the range of $0.25-5.0$ nmoles of xylitol. The reaction was followed by means of an Eppendorf fluorometer modified according to the recommendations of Estabrook, Williamson, Frenkel, and Maitra (20). Portions $(0.20$ $\mathrm{ml}$ ) of neutralized perchloric acid filtrates of washed erythrocytes that had been incubated with $5 \mathrm{~mm}$ glucose for $2 \mathrm{hr}$ were assayed for their xylitol content. In experiments using erythrocytes from three normal donors, no xylitol could be detected in the erythrocytes incubated with 5 or $50 \mathrm{~mm}$ glucose. If xylitol is present in the erythrocyte under these conditions, its concentration is less than $2.5 \mathrm{~m} \mu \mathrm{moles} / \mathrm{ml}$ of erythrocytes. In the same experiments the Sorbitol content, as assayed with sorbitol dehydrogenase, increased with increasing glucose concentration in each experiment (5.7 to $37.2 \mathrm{~m} \mu \mathrm{moles} / \mathrm{ml}$ red blood cell (RBC), 7.6 to 45.9 , and from 15.4 to 84.9 ). Thus, the reported increase in the sorbitol content of the erythrocyte when incubated with increasing glucose concentration cannot be attributed to a rise in erythrocyte xylitol concentration under these conditions.

Fructose was determined by means of a fluorometric assay using fructokinase prepared from rat liver. The assay system contained potassium phosphate buffer $\mathrm{pH} 7.0$ (50 $\mathrm{mm}$ ), $\mathrm{KCL}$ (10 $\mathrm{mm}$ ), $\mathrm{MgCl}_{2}$ (5 $\mathrm{mm}$ ), phosphoenolpyruvate (0.8 $\mathrm{mm})$, ATP $(0.05 \mathrm{~mm})$, NADH $(0.02 \mathrm{~mm})$, lactic dehydrogenase from rabbit muscle (7.5 IU), and pyruvate kinase from rabbit muscle ${ }^{7}$ (1.5 IU) in a final volume of $1.0 \mathrm{ml}$. The reaction resulting from the presence of pyruvate in the samples was completed within $2 \mathrm{~min}$, and at

ethylene glycol succinate; F-1, 6-diP, triose phosphates and fructose-1,6-diphosphate; F-6-P, fructose-6-phosphate; G6-P, glucose-6-phosphate; G-3-P, glyceraldehyde-3-phosphate; PEP, phosphoenolpyruvate ; 2-PGA, 2-phosphoglyceric acid; 3-PGA, 3-phosphoglyceric acid; $\mathrm{Pi}$, inorganic phosphate; RBC, red blood cell; TMS, trimethylsilyl.

${ }^{5}$ Brinkmann Instruments, Inc., Westbury, N. Y.

- Boehringer-Mannheim Corp., New York.

${ }^{7}$ Boehringer-Mannheim Corp. 
TABLE I

Lactate: Pyruvate Ratio

\begin{tabular}{|c|c|c|c|c|c|c|}
\hline \multicolumn{7}{|c|}{ After $2 \mathrm{hr}$ incubation with 5 and $50 \mathrm{~mm}$ glucose } \\
\hline $\begin{array}{l}\text { Medium } \\
\text { glucose }\end{array}$ & Lactate* & Pyruvate* & $\mathrm{L}: \mathrm{P}^{*}$ & $\begin{array}{c}\text { Glucose } \\
\text { consumption }\end{array}$ & $\begin{array}{c}\text { Lactate } \\
\text { production }\end{array}$ & Sorbitol \\
\hline$m \mathrm{M}$ & \multicolumn{2}{|c|}{$\mu m o l e s / m l \cdot R B C$} & & \multicolumn{2}{|c|}{ umoles/ml RBC per hr } & mumoles $/ m l R B C$ \\
\hline 5 & $9.08 \pm 1.25$ & $0.132 \pm 0.067$ & $69: 1$ & $1.66 \pm 0.23$ & $3.22 \pm 0.56$ & $20.94 \pm 9.13$ \\
\hline 50 & $9.48 \pm 1.52$ & $0.049 \pm 0.026$ & $193: 1$ & $1.82 \pm 0.27$ & $3.56 \pm 0.57$ & $89.56 \pm 30.11$ \\
\hline
\end{tabular}

Values expressed as the mean \pm SD of 11 experiments.

* Sampling of entire incubation mixture.

that point, $1.0 \mathrm{IU}$ of an ammonium sulfate suspension of rat liver fructokinase (20 IU per $\mathrm{mg}$ ) was added and the subsequent decrease in fluorescence due to the oxidation of NADH was determined. The reaction was completed within $10-15 \mathrm{~min}$. The assay is linear for fructose over the range of $0.125-1.5 \mathrm{~m} \mu$ moles in the presence of pyruvate concentrations as high as $5.0 \mathrm{~m} \mu \mathrm{moles} / \mathrm{ml}$. In practice, the pyruvate concentration of the samples was determined initially and the assay for fructose carried out with portions containing less than $2.0 \mathrm{~m} \mu$ moles of pyruvate. Glucose in concentrations as high as $10 \mu \mathrm{moles} / \mathrm{ml}$ do not interfere with the assay for fructose. It has been reported that $D$ xylulose and L-sorbose are also substrates for rat liver fructokinase, and it is possible that naturally occurring $D$ xylulose may contribute to the estimates of free fructose obtained by this enzymatic assay. We have previously reported that fructose can be demonstrated in erythrocytes and incubation medium by means of a gas-liquid chromatographic technique (11). However, the small quantities of free fructose that appear in the incubation media could not be accurately quantified in the presence of $50 \mathrm{~mm}$ glucose. For this reason the enzymatic assay for fructose was developed and utilized in these studies.

Gas-liquid chromatographic identification and quantification of fructose, "sorbitol" and other free sugars and polyols in erythrocytes was carried out as follows. Washed erythrocytes were incubated for $2 \mathrm{hr}$ in medium containing 5 or $50 \mathrm{~mm}$ glucose as described above. At the end of the incubation the suspensions were rapidly centrifuged and 2.0 $\mathrm{ml}$ portions of the erythrocyte layer (hematocrit $90 \%$ ) were pipetted into tubes containing $8.0 \mathrm{ml}$ of $\mathrm{Ba}(\mathrm{OH})_{2}$ $(0.3 \mathrm{~N})$, and $1.0 \mathrm{ml}$ of $\mathrm{H}_{2} \mathrm{O}$ containing $10 \mu \mathrm{g}$ of $\alpha$-methylmannopyranoside as an internal standard. After the cells had lysed, $8.0 \mathrm{ml}$ of zinc sulfate $(5 \%)$ was added and the protein free-filtrate obtained by centrifugation. $10-\mathrm{ml}$ portions were evaporated to dryness at room temperature and the trimethylsilyl (TMS) ethers of the sugars and polyols present in the extract were prepared by the method described by Sweeley, Bentley, Makita, and Wells (21). The samples were analyzed by means of a Packard instrument ${ }^{8}$ gas-liquid chromatographic apparatus using a 12 foot column of $15 \%$ ethylene glycol succinate (EGS) on 80/100 Chromosorb $\mathrm{W}^{\circ}$ at $165^{\circ} \mathrm{C}$ with a hydrogen flame detector.

For the determination of red cell $\left[1{ }^{14} \mathrm{C}\right] \mathrm{O}_{2}$ production, red cell suspensions were supplemented with glucose- $1-{ }^{14} \mathrm{C}^{10}$ $(137,000 \mathrm{cpm} / \mu \mathrm{mole})$ in concentrations ranging from 2 to $20 \mathrm{~mm}$ and incubations were conducted in $25-\mathrm{ml}$ flasks with

${ }^{8}$ Packard Instrument Co., Downers Grove, I11.

- Supelco, Inc., Bellefonte, Pa.

${ }^{10}$ New England Nuclear Corp., Boston, Mass. disposable rubber stoppers and removable plastic wells. After a $2 \mathrm{hr}$ period of incubation, the reactions were terminated by the addition of $0.5 \mathrm{ml}$ of $0.5 \mathrm{~N}$ perchloric acid and $0.3 \mathrm{ml}$ of iydroxide of Hyamine ${ }^{11}$ was added to the center wells. Trapping of $\mathrm{CO}_{2}$ was allowed to occur for $1 \mathrm{hr}$, after which time the center wells of the incubation flasks were removed and placed in scintillation vials containing 15 $\mathrm{ml}$ of $4.2 \%$ Liquifluor $^{10}$ (diluted in toluene).

Incubation studies in the presence of sodium pyruvate or sodium barbital were performed at 5 and $50 \mathrm{~mm}$ glucose, using the same methods of incubation and sampling as described above.

After $2 \mathrm{hr}$ of incubation at 5 and $50 \mathrm{~mm}$ glucose, the osmotic fragility of the erythrocytes was tested by the methods described by Dacie and Lewis (22). Cells were tested both before and after washing in $0.9 \% \mathrm{NaCl}$ containing $5 \mathrm{~mm}$ glucose.

In order to assess the leukocyte contribution to the Sorbitol and fructose measured in the extracts of the red cell suspensions, leukocyte-rich plasma was prepared by dextran sedimentation of whole heparinized blood. The supernatant plasma containing a total of 8-10 million leukocytes was centrifuged and the leukocyte button then extracted in perchloric acid and neutralized.

\section{RESULTS}

Erythrocyte sorbitol and fructose. Incubation with $50 \mathrm{~mm}$ glucose resulted in a significant increase in the concentration of sorbitol in the erythrocyte, as determined by means of fluorometric assay employing sheep liver sorbitol dehydrogenase (Table I). As noted in Methods, xylitol could not be detected in erythrocytes incubated with 5 or $50 \mathrm{~mm}$ glucose. Confirmation of the interpretation that the material measured is sorbitol was obtained by gas-liquid chromatographic analysis of the trimethylsilyl ethers prepared from protein-free filtrates of erythrocytes that had been incubated with 5 and $50 \mathrm{~mm}$ glucose. As shown in Fig. 1, small, but distinct peaks having the retention time of fructose and hexitol were present in filtrates prepared from cells incubated with $5 \mathrm{~mm}$ glucose. The quantities of fructose and hexitol were significantly increased in filtrates prepared from cells that had been incubated with $50 \mathrm{~mm}$ glucose. It should be noted that no distinct xylulose

${ }^{11}$ Rohm \& Haas Co., Philadelphia, Pa. 

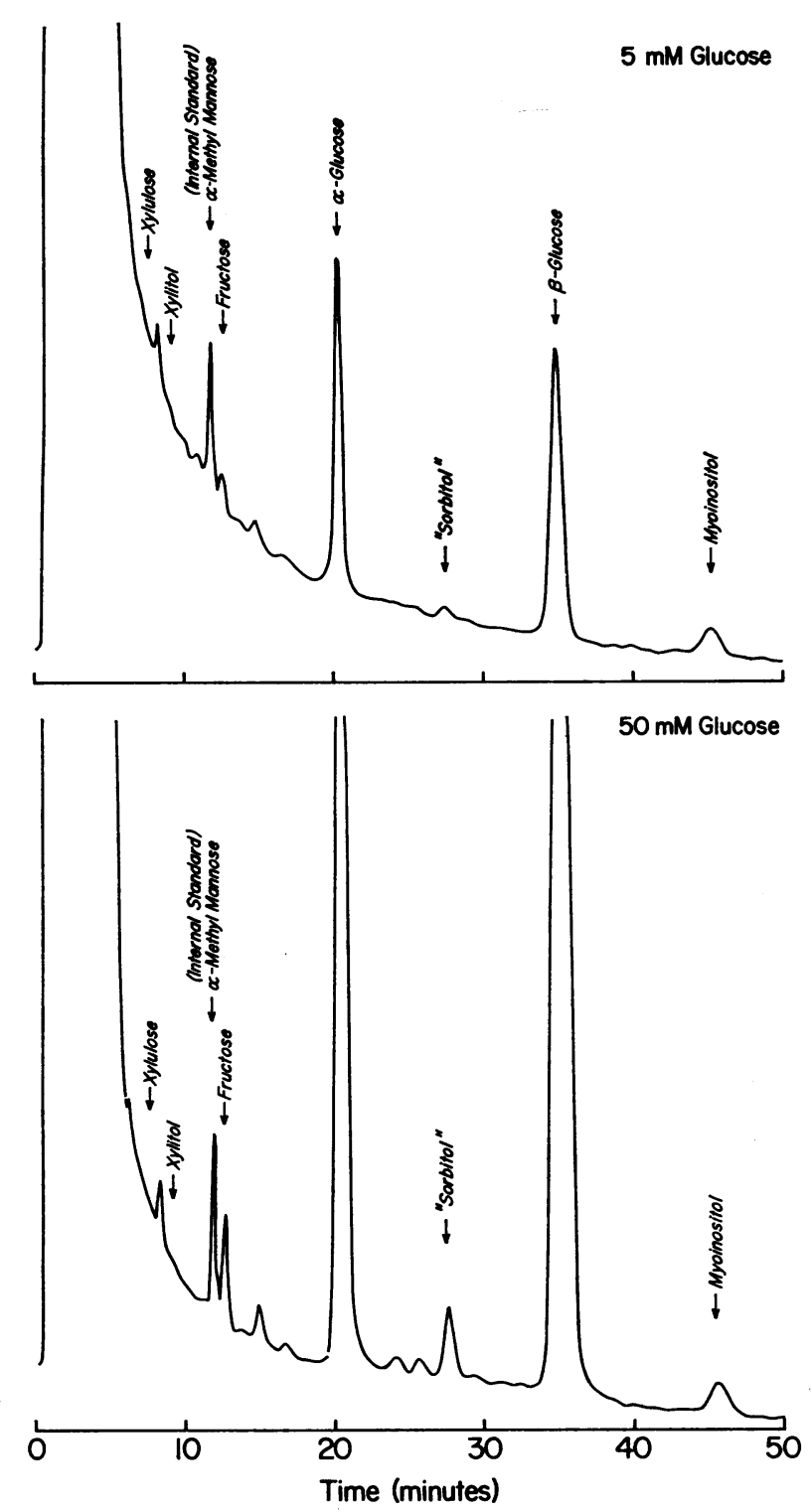

FIGURE 1 Gas-liquid chromatograms of the TMS derivatives of the sugars and polyols present in Somogyi filtrates of erythrocytes incubated for $2 \mathrm{hr}$ in medium containing $5 \mathrm{~mm}$ glucose (upper figure) or $50 \mathrm{~mm}$ glucose (lower figure). Details are listed in Methods. The retention time of xylulose and xylitol in this system are indicated, but neither was present in detectable concentrations. In this experiment, the Sorbitol concentration increased from 5.3 to $23.9 \mathrm{~m} \mu \mathrm{moles} / \mathrm{ml}$ of $\mathrm{RBC}$, and the fructose from 14.8 to $45.1 \mathrm{~m} \mu \mathrm{moles} / \mathrm{ml}$ of $\mathrm{RBC}$ with increasing medium glucose concentration.

(D plus L) or xylitol peak could be demonstrated in filtrates from cells incubated with 5 or $50 \mathrm{~mm}$ glucose. While the system employed in these studies does not permit the separation of sorbitol from other hexitols, the possibility that xylitol contributed to the values obtained by assay with sorbitol dehydrogenase has been clearly excluded. It appears reasonable to conclude that most of the "sorbitol" measured by assay with sorbitol dehydrogenase in the erythrocyte is in fact sorbitol. Sorbitol dehydrogenase is known to be present in the erythrocyte (23); the product of sorbitol oxidation by sorbitol dehydrogenase is fructose. Free nonphosphorylated fructose is present in erythrocytes incubated with $5 \mathrm{~mm}$ glucose (Fig. 1) and the concentration is higher in cells incubated with $50 \mathrm{~mm}$ glucose. It should also be noted that the levels of $\mathrm{L}$-xylulose present in the erythrocytes incubated with 5 or $50 \mathrm{~mm}$ glucose were undetectable (Fig. 1) and could not materially influence the values of erythrocyte fructose obtained by assay with fructokinase. These observations confirm our previous conclusion that increased ambient glucose concentration results in increased erythrocyte concentrations of both sorbitol and fructose.

Glucose consumption, lactate to pyruvate ratios. There was no significant difference in glucose consumption or lactate production by washed erythrocytes incubated with 5 or $50 \mathrm{~mm}$ glucose for $2 \mathrm{hr}$ (Table I). As anticipated from our previous observations, there was a significantly higher concentration of sorbitol in the erythrocytes incubated with $50 \mathrm{~mm}$ glucose (Table I). The total lactate recovered in the incubation suspension (erythrocytes plus medium) was unaltered by increasing the medium glucose concentration, however, the total pyruvate recovered was markedly decreased when $50 \mathrm{~mm}$ glucose was present (Table I). As a consequence, the ratio of lactate: pyruvate recovered in the incubation suspension at the end of the incubation rose from $69: 1$ to $193: 1$ with increasing medium glucose concentration. In experiments in which the lactate and pyruvate concentrations were determined in erythrocytes separated

TABLE II

Glycolytic Intermediates and ATP

\begin{tabular}{lcccc}
\hline & \multicolumn{4}{c}{ Washed erythrocytes } \\
\cline { 2 - 6 } \multicolumn{1}{c}{ Medium glucose, } & $m_{M}$ & 5 & & 50 \\
\hline Lactate* & 2.84 & \pm 0.39 & 3.19 & \pm 0.34 \\
Pyruvate* & 0.033 & \pm 0.014 & 0.009 & \pm 0.001 \\
L:P* & \multicolumn{2}{c}{$86: 1$} & $354: 1$ & \\
"Total triosephosphates" & 29.3 & \pm 12.8 & 677.9 & \pm 308.5 \\
2, 3-DPG & 5327 & \pm 625 & 4629 & \pm 743 \\
G-6-P & 31.6 & \pm 6.7 & 27.8 & \pm 6.9 \\
F-6-P & 11.6 & \pm 3.7 & 16.0 & \pm 4.7 \\
3-PGA & 59.5 & \pm 16.8 & 55.1 & \pm 9.1 \\
2-PGA & 7.7 & \pm 2.9 & 9.8 & \pm 5. \\
PEP & 22.3 & \pm 7.3 & 22.5 & \pm 55 \\
ATP & 1156 & \pm 75 & 1143 & \pm 77 \\
Sorbitol & 14.30 & \pm 2.57 & 82.70 & \pm 22.35 \\
Fructose & 35.53 & \pm 11.12 & 77.63 & \pm 26.87 \\
& & & & \\
\hline
\end{tabular}

Values expressed as the mean $\pm S D$ of 11 experiments.

* The values for lactate, pyruvate, and L:P are expressed as $\mu \mathrm{moles} / \mathrm{ml}$ suspension. All other values are expressed as $\mathrm{m} \mu \mathrm{moles} / \mathrm{ml} \mathrm{RBC}$. 
TABLE III

Erythrocyte ATP, 2, 3-DPG, and "Total Triose Phosphates"

\begin{tabular}{|c|c|c|c|c|c|}
\hline \multirow[b]{2}{*}{ Experiment } & \multicolumn{5}{|c|}{ After $2 \mathrm{hr}$ incubation with 5 and $50 \mathrm{~mm}$ glucose } \\
\hline & $\begin{array}{c}\text { Medium } \\
\text { glucose }\end{array}$ & ATP & 2, 3-DPG & $\Delta 2,3-\mathrm{DPG}$ & "TTP" \\
\hline & $m \mathbf{M}$ & & \multicolumn{3}{|c|}{ mumoles $/ m l R B C$} \\
\hline I & $\begin{array}{r}5 \\
50\end{array}$ & $\begin{array}{l}1108 \\
1115\end{array}$ & $\begin{array}{l}5498 \\
4320\end{array}$ & -1178 & $\begin{array}{r}16.4 \\
677.4\end{array}$ \\
\hline II & $\begin{array}{r}5 \\
50\end{array}$ & $\begin{array}{l}1181 \\
1159\end{array}$ & $\begin{array}{l}5084 \\
4884\end{array}$ & -2007 & $\begin{array}{c}16.95 \\
265.0\end{array}$ \\
\hline III & $\begin{array}{r}5 \\
50\end{array}$ & $\begin{array}{l}1158 \\
1252\end{array}$ & $\begin{array}{l}6166 \\
5652\end{array}$ & -514 & $\begin{array}{r}41.0 \\
1134.9\end{array}$ \\
\hline IV & $\begin{array}{r}5 \\
50\end{array}$ & $\begin{array}{l}1068 \\
1040\end{array}$ & $\begin{array}{l}4455 \\
3630\end{array}$ & -825 & $\begin{array}{r}43.3 \\
641.2\end{array}$ \\
\hline $\mathrm{V}$ & $\begin{array}{r}5 \\
50\end{array}$ & $\begin{array}{l}1265 \\
1150\end{array}$ & $\begin{array}{l}5434 \\
4658\end{array}$ & -776 & $\begin{array}{r}29.0 \\
671.1\end{array}$ \\
\hline & & & \multicolumn{3}{|c|}{ Mean $\begin{aligned} \Delta & =-699 \pm 164 \\
t & =4.26\end{aligned}$} \\
\hline
\end{tabular}

from incubation medium, the lactate: pyruvate ratio was 76:1 in cells that had been incubated with $5 \mathrm{~mm}$ glucose and 192:1 in cells that had been incubated with $50 \mathrm{~mm}$ glucose. In these experiments the ratio of lactate:pyruvate in the incubation medium rose from $21: 1$ to $170: 1$ with increasing medium glucose concentration.

Levels of glycolytic intermediates. A comparison of the levels of glycolytic intermediates present in erythrocytes, that had been incubated with 5 and $50 \mathrm{~mm}$ glucose (Table II), demonstrated a strikingly higher concentration of "total triose phosphates" in erythrocytes incubated with $50 \mathrm{~mm}$ glucose. There was, in addition, a lower concentration of 2,3,-DPG in erythrocytes that had been incubated with $50 \mathrm{~mm}$ glucose (Table II).

TABLE IV

Effect of Pyruvate on Triose Phosphate Accumulation

\begin{tabular}{|c|c|c|c|c|c|}
\hline \multirow[b]{2}{*}{ Medium glucose, } & \multicolumn{3}{|c|}{ "Total triose phosphate" } & \multicolumn{2}{|c|}{ 2, 3-DPG } \\
\hline & $m_{M}$ & 5 & 50 & 5 & 50 \\
\hline & \multicolumn{5}{|c|}{$m \mu m o l e s / m l R B C$} \\
\hline A & & & & & \\
\hline \multicolumn{6}{|l|}{$2 \mathrm{hr}$ incubation } \\
\hline No pyruvate & & 41.0 & 1134.9 & 6166 & 5652 \\
\hline $3 \mathrm{~mm}$ Pyruvate & & 7.5 & 21.5 & 4844 & 5248 \\
\hline \multicolumn{6}{|l|}{ B } \\
\hline 1st hr, no pyruvate & & & 432.8 & & \\
\hline \multicolumn{6}{|l|}{ 2nd hr } \\
\hline $0.25 \mathrm{~mm}$ Pyruvate & & & 33.5 & & \\
\hline $0.50 \mathrm{~mm}$ Pyruvate & & & 37.2 & & \\
\hline
\end{tabular}

Values expressed as $\mathrm{m} \mu \mathrm{moles} / \mathrm{ml} \mathrm{RBC}$.
The difference in 2,3-DPG concentration in paired samples incubated with 5 and $50 \mathrm{~mm}$ glucose was statistically significant (Table III). The concentration of glycolytic intermediates other than "total triose phosphates" and 2,3-DPG were similar in cells that had been incubated in 5 and $50 \mathrm{~mm}$ glucose (Table II).

In four subsequent experiments the effects of increasing medium glucose concentration on the individual components of "total triose phosphates" were examined. The levels of F-1, 6-diP, G-3-P, and DHAP were all higher in cells that had been incubated with $50 \mathrm{~mm}$ glucose. The mean F-1, 6-diP was 8.9 mumoles/ml RBC's with $5 \mathrm{~mm}$ glucose and 95.7 with $50 \mathrm{~mm}$ glucose. Similarly, the mean G-3-P concentrations were 3.1 and $57.8 \mathrm{~m} \mu \mathrm{moles} / \mathrm{ml}$ RBC's with 5 and $50 \mathrm{~mm}$ glucose, and the mean DHAP concentrations were 20.9 and 214.1 $\mathrm{m} \mu \mathrm{moles} / \mathrm{ml} \mathrm{RBC}$ 's with 5 and $50 \mathrm{~mm}$ glucose.

The possible contribution of leukocytes in the washed red cells to the values obtained for the concentrations of sorbitol and glycolytic intermediates was examined. As noted in Methods, the final erythrocyte suspensions contained less than 200 leukocytes $/ \mathrm{mm}^{8}$. The levels of glycolytic intermediates in neutralized perchlorate filtrates prepared from 8 to $10 \times 10^{\circ}$ leukocytes were undetectable by the methods employed in these studies. The concentration of sorbitol averaged $14.7 \mathrm{~m} \mu$ moles per $10^{7}$ leukocytes. These findings suggest that leukocyte contamination does not significantly contribute to the values for sorbitol or glycolytic intermediates reported herein.

Effect of sodium pyruvate. When sodium pyruvate ( $3 \mathrm{mM}$ ) was present in the medium the concentration of "total triose phosphates" in erythrocytes incubated 
TABLE $\mathrm{V}$

Incubation of Washed Erythrocytes at 5 and $50 \mathrm{~mm}$ Glucose with and without $3.3 \mathrm{~m}$ Sodium Barbital

\begin{tabular}{lcccc}
\hline & \multicolumn{2}{c}{ No barbital } & \multicolumn{2}{c}{$3.3 \mathrm{~mm}$ barbital } \\
\hline Medium glucose, $m \mathrm{M}$ & 5 & 50 & 5 & 50 \\
Lactate* & 2.59 & 3.09 & 2.47 & 2.77 \\
Pyruvate* & 0.045 & 0.012 & 0.091 & 0.031 \\
L:P* & $58: 1$ & $258: 1$ & $27: 1$ & $89: 1$ \\
"Total triose phosphate" & 19.0 & 538.1 & 9.52 & 64.8 \\
2, 3-DPG & 5872 & 4404 & 4221 & 4771 \\
Sorbitol & 12.4 & 107.0 & 6.7 & 13.0 \\
\hline
\end{tabular}

* Expressed as $\mu$ moles $/ \mathrm{ml}$ cells-buffer. Other values expressed as $\mathrm{m} \mu \mathrm{moles} / \mathrm{ml}$ RBC.

with $50 \mathrm{~mm}$ glucose was $1 / 50$ th that of erythrocytes incubated with $50 \mathrm{~mm}$ glucose alone (Table IV, A). The presence of pyruvate thus prevented the marked accumulation of "total triose phosphates" that occurs when erythrocytes are incubated with $50 \mathrm{~mm}$ glucose. After cells had been incubated with $50 \mathrm{~mm}$ glucose for $1 \mathrm{hr}$ the addition of as little as $0.25 \mathrm{~mm}$ pyruvate to the medium not only prevented further "triose phosphate" accumulation, but restored their concentration toward base line values (Table IV, B). We found, as previously described by Rose and Warms (24), that $0.25 \mathrm{~mm}$ pyruvate does not stimulate pentose-phosphate pathway activity.

Incubation with sodium barbital. When washed erythrocytes were incubated for $2 \mathrm{hr}$ with 5 and $50 \mathrm{~mm}$ glucose in the presence of $3.3 \mathrm{~mm}$ sodium barbital, sorbitol accumulation was markedly inhibited. There was a corresponding diminution in the metabolic alterations that usually accompany exposure to $50 \mathrm{~mm}$ glucose, such as a rise in the lactate: pyruvate ratio, accumulation of "total triose phosphates" and a decrease in 2,3-DPG concentration (Table V).

$\left[1-{ }^{14} \mathrm{C}\right] \mathrm{O}$, production. With increasing media glucose concentration, there was an associated increase in the red cell $\left[1-{ }^{14} \mathrm{C}\right] \mathrm{O}_{2}$ production (Table VI). Because there was no increase in over-all red cell glucose consumption, this resulted in an increase in the per cent of glucose consumed that appeared as $\left[1-{ }^{14} \mathrm{C}\right] \mathrm{O}_{2}$. The shunt activity rose from a mean of $5.2 \%$ at $2 \mathrm{~mm}$ to $9.0 \%$ at $20 \mathrm{~mm}$ glucose.

When cells were incubated with glucose- $2-{ }^{14} \mathrm{C}$ at varying medium glucose concentrations, no such increase in carbon dioxide production was observed.

Osmotic fragility studies. When osmotic fragility was examined in washed red cells that had been incubated with 5 and $50 \mathrm{~mm}$ glucose for $2 \mathrm{hr}$, the cells incubated in $50 \mathrm{~mm}$ glucose showed decreased resistance to osmotic stress. However, when these cells were washed in physiologic saline or saline with $5 \mathrm{~mm}$ glucose before testing, the osmotic fragility of both the 5 and $50 \mathrm{~mm}$ samples was within the normal range.

\section{DISCUSSION}

The glucose concentration in human erythrocytes approximates that of the ambient medium glucose concentration (25), and under physiological conditions it is far in excess of the $K_{m}$ 's for glucose of the erythrocyte hexokinases (26). It follows that under most circumstances, the ambient glucose concentration, and the rate of intracellular transport of glucose is not rate limiting for glucose metabolism by the major pathways that require its initial phosphorylation to glucose-6-phosphate.

In previous investigations (11) we had observed that the concentration of sorbitol in washed human erythrocytes rose from 20.9 to $89.6 \mathrm{~m} \mu$ moles $/ \mathrm{ml}$ of $\mathrm{RBC}$ during a $2 \mathrm{hr}$ incubation when the medium glucose concentration was increased from 5 to $50 \mathrm{~mm}$. This increase in erythrocyte sorbitol concentration was associated with an increase in erythrocyte fructose concentration from 37.6 to $96.7 \mathrm{~m} \mu \mathrm{moles} / \mathrm{ml} \mathrm{RBC}$ and an increase in the quantity of free fructose recovered in the medium. These observations suggested that glucose conversion to sorbitol and fructose was increased in human erythrocytes as a consequence of the increased intracellular concentration of glucose. The data presented in this report support this conclusion.

TABLE VI

$\left[1-{ }^{14} \mathrm{C}\right] \mathrm{O}_{2}$ Production

\begin{tabular}{|c|c|c|c|}
\hline $\begin{array}{l}\text { Medium } \\
\text { glucose }\end{array}$ & $\begin{array}{c}\text { Glucose } \\
\text { consumption }\end{array}$ & $\begin{array}{c}{[1-14 \mathrm{C}] \mathrm{O}_{2}} \\
\text { production }\end{array}$ & $\begin{array}{c}\text { Glucose } \\
\text { consumption }\end{array}$ \\
\hline$m M$ & \multicolumn{2}{|c|}{ umoles $/ \mathrm{ml} R B C$ per $\mathrm{hr}$} & $\%$ \\
\hline 2 & $1.53 \pm 0.15$ & $0.080 \pm 0.05$ & 5.23 \\
\hline 5 & $1.60 \pm 0.18$ & $0.092 \pm 0.05$ & 5.75 \\
\hline 10 & $1.66 \pm 0.22$ & $0.117 \pm 0.08$ & 7.05 \\
\hline 20 & $1.75 \pm 0.26$ & $0.157 \pm 0.09$ & 8.95 \\
\hline
\end{tabular}

Values expressed as the mean \pm SD of five experiments. 
The enzyme responsible for the reduction of glucose to sorbitol in human erythrocytes has not not been isolated as yet. Both aldose reductase (alditol: NADP oxidorectase) and L-gulonate: NADP oxidoreductase isolated from mammalian tissues catalyze the NADPH-dependent reduction of glucose when the sugar is present in sufficiently high concentrations. However, the $K_{m}$ 's for glucose of the L-gulonate: NADP oxidoreductases isolated from mammalian tissues are so high that it is doubtful that glucose is a substrate under physiological conditions $(2,8-10)$. In human aorta, aldose reductase has a $K_{m}$ glucose of the order of $10^{-1} \mathrm{M}$; the $K_{m}$ for glucose of the L-gluonate: NADP oxidoreductase in the same tissue is in excess of $2.0 \mathrm{~m}$. The presence of sorbitol in freshly isolated erythrocytes from normal humans, therefore, suggests that the enzyme responsible for sorbitol formation is the ubiquitous alditol: NADP oxidoreductase.

The high $K_{m}$ glucose of the enzyme(s) responsible for the synthesis of sorbitol in most mammalian tissues provides an adequatae explanation for the increased rate of sorbitol and fructose synthesis which results from increased intracellular glucose concentration in human erythrocytes. Sorbitol dehydrogenase is known to be present in human erythrocytes and is presumably responsible for the oxidation of sorbitol to fructose (23). The normal function of the polyol pathway in human erythrocytes is unknown, although it accounts for 2-3\% of the glucose uptake at physiological ambient glucose concentrations and as much as $11 \%$ at $50 \mathrm{~mm}$ glucose (11).

The data presented in this report indicate that increasing intracellular glucose concentration, by raising the medium concentration from 5 to $50 \mathrm{~mm}$, does not significantly alter total glucose consumption or the rate of lactate production. There is, however, a marked increase in the ratio of erythrocyte lactate to pyruvate concentrations which results primarily from a decrease in pyruvate. Krebs and Veech (27) have pointed out that the steady states of a number of NAD-dependent dehydrogenase reactions in the cytoplasm are in near equilibrium. (For example, the mass action ratios of these systems closely approximate the equilibrium constant of the reaction.) In liver the levels of lactic dehydrogenase activity are sufficiently high that the oxidized and reduced metabolites of the system are practically in equilibrium with the free nucleotides according to the equation:

$$
\frac{(\text { free } \mathrm{NAD})}{\left(\text { free } \mathrm{NADH}_{2}\right)}=\frac{1}{K} \times \frac{(\text { pyruvate })}{\text { (lactate })}
$$

where $K$ is the equilibrium constant divided by the $\mathrm{H}^{+}$ concentration. The ratio of free $\mathrm{NAD} /$ free $\mathrm{NADH}_{2}$ can thus be estimated from the steady-state pyruvate to lac- tate ratio if the equilibrium constant for $\mathrm{pH}$, ionic strength, and temperature appropriate to the cytoplasm is known. It would follow that the observed decrease in the ratio of the pyruvate to lactate concentrations, observed in erythrocytes incubated with $50 \mathrm{~mm}$ glucose, probably reflects a decrease in the free $\mathrm{NAD} /$ free $\mathrm{NADH}_{2}$ ratio.

Minakami and Yoshikawa (28) have demonstrated that under physiological conditions in human erythrocytes the activities of glyceraldehyde-3-phosphate dehydrogenase and phosphoglycerate kinase are sufficiently high with respect to the other enzymes of glycolysis that the combined systems are in near equilibrium. Krebs and Veech (27) have recently pointed out that the data of Minakami and Yoshikawa indicate that the following relationship holds for human red blood cells as a consequence of the fact that both the lactic dehydrogenase and the glyceraldehyde-3-phosphate dehydrogenase/ phosphoglycerate kinase systems are in equilibrium with a common pool of free NAD and free $\mathrm{NADH}_{2}$.

$$
\begin{aligned}
\frac{(\text { Pyruvate })}{(\text { Lactate })}=\frac{K \text { lactic dehydrogenase }}{K \text { GAPDH } \times} & \text { K 3-PGA kinase } \\
& \times \frac{3-P G A}{\mathrm{G}-3-\mathrm{P}} \times \frac{(\mathrm{ATP})}{(\mathrm{ADP})}(\mathrm{Pi}) .
\end{aligned}
$$

There is no significant change in ATP in erythrocytes incubated with $50 \mathrm{~mm}$ glucose. If one assumes that there are no significant changes in ADP or inorganic phosphate $(\mathrm{Pi})$ under these conditions, a decrease in the ratio of (free $\mathrm{NAD}) /\left(\right.$ free $\mathrm{NADH}_{2}$ ) indicated by a change in the (pyruvate)/(lactate) ratio, would result in a decrease in the 3-PGA/G-3-P ratio. This would result in a rise in the steady state levels of G-3-P, DHAP, and fructose-1,6-diP, since Minakami and Yoshikawa have demonstrated that the over-all reaction catalyzed by aldolase and triose phosphate isomerase is in a near-equilibrium state. This interpretation is supported by the observation that the addition of pyruvate which results in an increased (free $\mathrm{NAD}) /\left(\right.$ free $\mathrm{NADH}_{2}$ ) ratio by means of its reaction with the lactic dehydrogenase system, reduces the concentrations of G-3-P, DHAP, and fructose-1,6-diP in erythrocytes incubated with 50 mM glucose.

The reduced (free NAD)/(free NADH) ratio in erythrocytes incubated with $50 \mathrm{~mm}$ glucose probably results from increased sorbitol oxidation to fructose by the NAD linked sorbitol dehydrogenase. This speculation is supported by the observation that barbital, which inhibits sorbitol synthesis by aldose reductase ${ }^{12}$ or L-gulonate: NADP oxidoreductase (29), reduced the lactate:pyruvate ratio. Under these circumstances there was a significant reduction in the levels of total triose-

\footnotetext{
${ }^{12}$ Clements, R. S., Jr. Unpublished data.
} 
phosphaate. Asakura, Adachi, Minakami, and Yoshikawa (30) found that the addition of 10 or $100 \mathrm{~mm}$ xylitol, a substrate for sorbitol dehydrogenase, resulted in significant increases in erythrocyte DHAP concentration in cells incubated with $10 \mathrm{~mm}$ glucose. Under these conditions a significant increase in the lactate to pyruvate ratio was also observed.

The increase in sorbitol production with increasing medium glucose concentration also appears to result in an increase in the free NADP/free NADPH ratio. This is reflected in the increase in $1-{ }^{14} \mathrm{C} \mathrm{O}_{2}$ production by the red cell at increasing glucose concentrations, since under normal circumstances, the NADP concentration regulates the activity of the pentose phosphate pathway at the glucose-6-phosphate dehydrogenase (G-6-PD) step (31). Kinoshita, Futterman, Satch, and Merola (32) observed a linear increase in $\left[1{ }^{14}{ }^{4} \mathrm{C}_{2}\right.$ production in rabbit lens when incubated with 5 to $30 \mathrm{~mm} 1{ }^{14} \mathrm{C}-$ glucose. These workers interpreted their results in a similar fashion.

The decrease in the concentration of 2,3-DPG in erythrocytes incubated with $50 \mathrm{~mm}$ glucose, and the unaltered rate of lactate production forces the consideration that under these circumstances 2,3-DPG makes a significant contribution to lactate and ATP production. It has recently been reported (33) that in the erythrocyte deprived of glucose, 2,3-diphosphoglycerate disappearance can be quantitatively accounted for by ATP and lactate production during short periods of incubation.

The observation that the erythrocytes of diabetics with hyperglycemia have an increased sorbitol content (11), suggests that other metabolic alterations in red cell metabolism, such as a decreased 2,3-diphosphoglycerate concentration, may occur in vivo as a consequence of increased polyol pathway activity. 2,3-Diphosphoglycerate is the erythrocyte organic phosphate that is quantitatively most important with respect to modulation of hemoglobin oxygen affinity. A change in 2,3-diphosphoglycerate concentration of approximately $0.5 \mu$ moles $/ \mathrm{ml}$ RBC's produces a corresponding change in the $\mathrm{P}_{50}$ (the partial pressure of oxygen required for $50 \%$ saturation of hemoglobin) of $1 \mathrm{~mm} \mathrm{Hg}$ (34). Prolonged hyperglycemia might thus be anticipated to produce a lowering of red cell 2,3-DPG and an accompanying increase in the affinity of hemoglobin for oxygen. Although the red cell 2,3-DPG concentration has previously been found to be reduced in diabetics with ketoacidosis (35) this decrease has been attributed to the low blood $\mathrm{pH}$ rather than to the associated hyperglycemia.

In this study, no osmotic consequences of polyol accumulation in the erythrocyte could be demonstrated. Although the physiologic role of the polyol pathway remains to be determined, the results of the study of this pathway appear to provide the first example of an alteration of normal red cell metabolism produced by an excess of its normal substrate glucose.

\section{REFERENCES}

1. Van Heyningen, R. 1959. Formation of polyols by the lens of the rat with sugar cataract. Nature (London). 184: 194.

2. Clements, R. S., Jr., J. P. Weaver, and A. I. Winegrad. 1969. The distribution of polyol: NADP oxidoreductase in mammalian tissues. Biochem. Biophys. Res. Commun. $37: 347$.

3. Hers, H. G. 1960 . L'Aldose-Réductase. Biochim. Biophys. Acta. 37: 120.

4. Van Heyningen, R. 1962. The sorbitol pathway in the lens. Exp. Eye Res. 1: 396.

5. Kinoshita, J. H., L. O. Merola, and E. Dikmak. 1962. Osmotic changes in experimental galactose cataracts. Exp. Eye Res. 1: 405.

6. Gabbay, K. H., L. O. Merola, and R. A. Field. 1966. Sorbitol pathway: presence in nerve and cord with substrate accumulation in diabetes. Science (Washington). 151: 209.

7. Stewart, M. A., W. R. Sherman, M. M. Kurien, G. I. Moonsammy, and M. Wisgerhof. 1967. Polyol accumulations in nervous tissue of rats with experimental diabetes and galactosaemia. J. Neurochem. 14: 1057.

8. Hayman, S., and J. H. Kinoshita. 1965. Isolation and properties of lens aldose reductase. J. Biol. Chem. 240: 877.

9. Moonsammy, G. I., and M. A. Stewart. 1967. Purification and properties of brain aldose reductase and Lhexonate dehydrogenase. J. Neurochem. 14: 1187.

10. Clements, R. S., Jr., A. D. Morrison, and A. I. Winegrad. 1969. Polyol pathway in aorta: regulation by hormones. Science (Washington). 166: 1007.

11. Morrison, A. D., R. S. Clements, Jr., S. B. Travis, F. Oski, and A. I. Winegrad. 1970. Glucose utilization by the polyol pathway in human erythrocytes. Biochem. Biophys. Res. Commun. 1: 199.

12. Slein, M. W. 1963. D-Glucose. Determination with hexokinase and glucose-6-phosphate dehydrogenase. In Methods of Enzymatic Analysis. H. U. Bergmeyer, editor. Academic Press Inc., New York. 1st edition. 117.

13. Hohorst, H. J. 1963 L- (+)-Lactate. Determination with lactic dehydrogenase and DPN. In Methods of Enzymatic Analysis. H. U. Bergmeyer, editor. Academic Press Inc., New York. 1st edition, 266.

14. Lamprecht, W., and I. Trautschold. 1963. Adenosine-5'triphosphate. Determination with hexokinase and glucose-6-phosphate dehydrogenase. In Methods of Enzymatic Analysis. H. U. Bergmeyer, editor. Academic Press Inc., New York. 1st edition. 543.

15. Hadjivassiliou, A. G., and S. V. Rieder. 1968. The enzymatic assay of pyruvic and lactic acids. A definitive procedure. Clin. Chim. Acta. 19: 357.

16. Lowry, O. H., J. V. Passonneau, F. X. Hasselberger, and D. W. Schultz. 1964. Effect of ischemia on known substrates and cofactors of the glycolytic pathway in brain. J. Biol. Chem. 239: 18.

17. Keitt, A. S. 1969. Hemolytic anemia with impaired hexokinase activity. J. Clin. Invest. 48: 1997.

18. Schröter, W., and H. v. Heyden. 1965. Kinetik des 2,3Diphosphoglyceratumsatzes in menschlichen Erythrocyten. Biochem. Z. 341: 387. 
19. Krimsky, I. 1963. D-2,3-diphosphoglycerate. In Methods of Enzymatic Analysis. H. U. Bergmeyer, editor. Academic Press Inc., New York. 1st edition. 238.

20. Estabrook, R. W., J. R. Williamson, R. Frenkel, and P. K. Maitra. 1967. The fluorometric determination of mitochondrial adenine and pyridine nucleotides. Methods Enzymol. 10: 474.

21. Sweeley, C. C., R. Bentley, M. Makita, and W. W. Wells. 1963. Gas-liquid chromatography of trimethylsilyl derivatives of sugars and related substances. J. Amer. Chem. Soc. 85: 2497.

22. Dacie, J. V., and S. M. Lewis. 1963. Practical Hematology. Grune \& Stratton, Inc., New York. 3rd edition. 135.

23. Morsches, B., H. Holzmann, and C. Bettingen. 1969. Zum nachweis der sorbit-dehydrogenase in menschlichen erythrocyten. Klin. Wochenschr. 47: 672.

24. Rose, I. A., and J. V. B. Warms. 1966. Control of glycolysis in the human red blood cell. J. Biol. Chem. 241 : 4848.

25. Wilbrandt, W., S. Frei, and T. Rosenberg. 1956. The kinetics of glucose transport through the human red cell membrane. Exp. Cell Res. 11: 59.

26. Garby, L., and C. H. deVerdier. 1964. Glucose metabolism in normal erythrocytes. I. Kinetics of the hexokinase reaction in intact cells. Scand. J. Haematol. 1: 150.

27. Krebs, H. A., and R. L. Veech. 1969. Pyridine nucleotide interrelations. In The Energy Level and Metabolic Control in Mitochondria. T. Popa, editor. Adriatica Ediatrice, Bari, Italy. 329.
28. Minakami, S., and H. Yoshikawa. 1966. Studies on erythrocyte glycolysis. II. Free energy changes and rate limiting steps in erythrocyte glycolysis. J. Biochem. (Tokyo). 59: 139 .

29. Mano. Y., K. Suzuki, K. Yamada, and N. Shimazono. 1961. Enzymic studies on TPN L-hexonate dehydrogenase from rat liver. J. Biochem. (Tokyo). 49: 618 .

30. Asakura, T., K. Adachi, S. Minakami, and H. Yoshikawa. 1967. Non-glycolytic sugar metabolism in human erythrocytes. I. Xylitol metabolism. J. Biochem. (Tokyo). 62: 184

31. Sturman, J. A. 1967. Pentose phosphate pathway metabolism by normal and glucose-6-phosphate dehydrogenasedeficient human red cell hemolyzates. Clin. Chim. Acta. 18: 245 .

32. Kinoshita; J. H., S. Futterman, K. Satoh, and L. O. Merola. 1963. Factors affecting the formation of sugar alcohols in ocular lens. Biochim. Biophys. Acta. 74: 340.

33. Feig, S. A., S. B. Shohet, and D. G. Nathan. 1970. ATP and 2,3-DPG utilization by the membranes of glucose free human RBC. Blood. 36: 838. (Abstr.)

34. Oski, F. A., A. J. Gottlieb, W. W. Miller, and M. Delivoria-Papadopoulos. 1970. The effects of deoxygenation of adult and fetal hemoglobin on the synthesis of red cell 2,3-diphosphoglycerate and its in vivo consequences. J. Clin. Invest. 49: 400.

35. Lenfant, C. 1970. In Red Cell Metabolism and Function. G. Brewer, editor. Plenum Publishing Corporation, New York. 359. 